\title{
C14ORF166 overexpression is associated with pelvic lymph node metastasis and poor prognosis in uterine cervical cancer
}

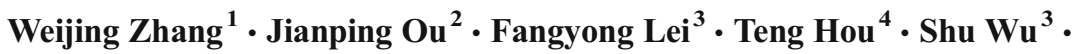 \\ Chunhao Niu ${ }^{1}$ - Liqun $\mathrm{Xu}^{5}$ - Yanna Zhang ${ }^{1}$
}

Received: 6 May 2015 / Accepted: 20 July 2015 / Published online: 29 July 2015

(C) The Author(s) 2015. This article is published with open access at Springerlink.com

\begin{abstract}
C14ORF166 (chromosome 14 open reading frame 166 ) is a transcriptional repressor related to the regulation of centrosome architecture. However, the role of C14ORF166 in the development and progression of cancer remains largely unknown. The aim of this study was to investigate the expression and clinicopathological significance of C14ORF166 in cervical cancer. C14ORF166 expression was analyzed using quantitative real-time PCR (RT-PCR) and Western blotting in cervical cancer cell lines and eight paired cervical cancer samples and the adjacent normal tissues. Immunohistochemistry
\end{abstract}

Weijing Zhang and Jianping Ou contributed equally to this work.

\author{
Yanna Zhang \\ zhangyn@sysucc.org.cn \\ Weijing Zhang \\ zhangwj@sysucc.org.cn \\ Jianping Ou \\ dr.oujianping@gmail.com \\ Fangyong Lei \\ leify@sysucc.org.cn \\ Teng Hou \\ laiyan@163.com \\ Shu Wu \\ wushu@sysucc.org.cn \\ Chunhao Niu \\ niuchh@sysucc.org.cn \\ Liqun $\mathrm{Xu}$ \\ xuliqunyang@126.com
}

was used to analyze C14ORF166 protein expression in 148 clinicopathologically characterized cervical cancer specimens. Statistical analyses were performed to evaluate the relationship between the expression of C14ORF166 and clinicopathologic features and prognosis. C14ORF166 mRNA and protein expression were significantly upregulated in cervical cancer cell lines and tissue samples $(P<0.05)$. Immunohistochemical analysis revealed a high expression of C14ORF166 was observed in $39.9 \%$ (59/148) of the cervical cancer specimens; the remaining samples expressed low

2 Center for Reproductive Medicine, The Third Affiliated Hospital of Sun Yat-Sen University, No. 600, Tian He Road, GuangZhou 510630, People's Republic of China

\footnotetext{
State Key Laboratory of Oncology in South China, Collaborative Innovation Center for Cancer Medicine, Guangzhou 510060, People's Republic of China
}

4
1 Department of Gynecologic Oncology; State Key Laboratory of Oncology in South China; Collaborative Innovation Center for Cancer Medicine, Cancer Center, Sun Yat-Sen University, No. 651, Dongfeng Road East, Guangzhou 510060,

People's Republic of China

\footnotetext{
Department of Gynecology, Women and Children Hospital of Guangdong Province, No. 13, Guang Yuan Road, Guangzhou 510060, People's Republic of China
} 
levels or did not express any detectable C14ORF166. The chisquare test indicated that high-level expression of C14ORF166 was significantly associated with International Federation of Gynecology and Obstetrics (FIGO) stage $(P<0.001)$, vital status $(P=0.026)$, tumor size $(P=0.034)$, serum squamous cell carcinoma antigen level (SCC-Ag; $P=$ $0.035)$, and pelvic lymph node metastasis $(P<0.001)$. Patients with highly expressed C14ORF166 showed a tendency to receive postoperative chemotherapy $(P=0.005)$ and postoperative radiation $(P=0.008)$. Furthermore, high C14ORF166 expression was associated with poorer overall survival compared to low C14ORF166 expression, and C14ORF166 was a significant prognostic factor in univariate and multivariate analysis $(P<0.05)$. High $\mathrm{C} 14 \mathrm{ORF} 166$ expression had prognostic value for poor outcome in cervical cancer. C14ORF166 may represent a biomarker of pelvic lymph node metastasis and enable the identification of high-risk patients along with selection of appropriate treatment strategies.

Keywords C14ORF166 · Cervical cancer · Lymph node metastasis $\cdot$ Prognosis $\cdot$ Biomarker

\section{Introduction}

Cervical cancer is the third most common malignancy among females worldwide, with an estimated global incidence of more than 500,000 new cases and 260,000 deaths every year [1]. Cervical cancer is prevalent in developing countries, where it remains a major cause of mortality among females [2]. Viral infection, genetic susceptibility, and environmental factors are associated with the etiology of cervical cancer. The development of cervical lesions from cervical intraepithelial neoplasia $(\mathrm{CIN})$ to cervical cancer is a complicated process that is initiated by persistent infection with high-risk types of human papillomavirus (HPV) [3]. Altered expression of a variety of oncogenes and tumor suppressor genes has also been associated with cervical cancer [4]. However, the precise mechanisms that regulate the pathogenesis of cervical cancer are poorly characterized, and a specific genetic signature to predict prognosis has not yet been identified in cervical cancer. Conventional clinical, diagnostic, and pathological variables such as International Federation of Gynecology and $\mathrm{Ob}-$ stetrics (FIGO) stage, tumor size, and the depth of infiltration are still used extensively to predict prognosis but are not sufficiently reliable to predict clinical outcome [5]. Patients with lymph node metastasis have a higher rate of mortality than patients without lymph node metastasis [6], and assessment of lymph node metastasis provides important information for determining the appropriate treatment approach [7]. Hence, it would be of clinical significance to identify biomarkers of lymph node metastasis or prognostic factors in patients with cervical cancer.
C14ORF166 is located on chromosome 14 at 14q22.1 and encodes a highly conserved $28-\mathrm{kDa}$ protein. C14ORF166 was originally identified as an influenza A virus-associated gene and may modulate transcription by interacting with various transactivators [8]. C14ORF166 has been suggested to play a prominent role in the fate of nuclear and cytoplasmic RNA. The C14ORF166-DDX1-HSPC117-FAM98B complex is present in both cellular compartments and transports RNA molecules between the nucleus and the cytoplasm [9]. Interestingly, overexpression of C14ORF166 has been observed in a variety of human cancers. Wang et al. [10] reported that C14ORF166 is highly expressed in a variety of brain tumors and is differentially expressed during normal brain development. Recently, C14ORF166 was reported to be a potential biomarker for metastasis in patients with human pancreatic carcinoma [11, 12]. Along with acylglycerol kinase (AGK), C14ORF166 has been implicated in the JAK2/STAT3 signaling pathway in esophageal squamous cells [13]. The JAK2/ STAT3 pathway has been reported to play a crucial role in regulating the progression of cervical cancer $[14,15]$. However, the protein expression level and role of C14ORF166 in cervical cancer have not been investigated.

In the current study, we aimed to explore the expression of C14ORF166 in cervical cell lines and human cervical tissues. Moreover, we investigated the association between the expression of C14ORF166 protein and clinical significances and survival outcomes of a cohort of 148 patients with cervical cancer.

\section{Methods}

\section{Cell lines}

Patient consent was obtained prior to the use of the clinical materials for research purposes, and the patient consent and protocol were approved by Sun Yat-Sen University Cancer Center Institutional Review Board. A primary culture of normal cervical epithelial cells was established from a biopsy of noncancerous cervical epithelium and was cultured in complete Keratinocyte-SFM medium (Invitrogen, Carlsbad, CA, USA). The cervical cancer cell lines HeLa, SiHa, C33A, MS751, CasKi, HeLa229, and HCC94 were cultured in RPMI-1640 medium (GIBCO BRL), and ME-180 was cultured in DMEM medium (Gibco, Grand Island, NY, USA), all supplemented with $10 \%$ fetal bovine serum (HyClone Laboratories, Logan, UT).

\section{Patients and tissue samples}

For real-time PCR (RT-PCR) and Western blot analysis, we collected 8 paired cervical cancers and adjacent normal tissues from the patients who underwent surgery between 2013 and 
2014. A total of 148 cases of paraffin-embedded cervical cancer samples had been clinically and histologically diagnosed at the Sun Yat-Sen University Cancer Center (Guangzhou, China) from 2001 to 2005. Clinical and clinicopathological classification and staging of all the patients were defined according to the International Federation of Gynecology and Obstetrics (FIGO) criteria (Pecorelli, 2009): 51 were respectively allocated to stage I; 80 to stage II; 15 to stage III; and 2 to stage IV. The patients' age ranged from 25 to 68 years (mean, 42.57 years). Clinicopathological characteristics of the tumor cases are presented in Table 1. The follow-up time of the cohort ranged from 2 to 132 months, with a median follow-up time of 51.65 months.

\section{Real-time PCR}

Total RNA samples from cell lines and fresh surgical cervical cancer tissue were isolated using Trizol reagent (Invitrogen, Carlsbad, CA, USA) according to the manufacturer's instructions. The extracted RNA was pretreated with RNase-free DNase, and approximately $2 \mu \mathrm{g}$ of RNA from each sample was used for cDNA synthesis primed with random hexamers. For the PCR amplification of C14ORF166 cDNA, an initial amplification step using C14ORF166-specific primers was performed with denaturation at $95{ }^{\circ} \mathrm{C}$ for $10 \mathrm{~min}$. This was followed by 28 denaturation cycles at $95{ }^{\circ} \mathrm{C}$ for $60 \mathrm{~s}$, primer annealing at $58{ }^{\circ} \mathrm{C}$ for $30 \mathrm{~s}$, and a primer extension phase at $72{ }^{\circ} \mathrm{C}$ for $30 \mathrm{~s}$. Upon the completion of the cycling steps, a final extension step at $72{ }^{\circ} \mathrm{C}$ for 5 min was performed before the reaction mixture was stored at $4{ }^{\circ} \mathrm{C}$. Real-time PCR was then employed to determine the increase of C14ORF166 mRNA in each of the primary cervical tumors relative to the paired normal cervical tissue taken from the same patient. The primers were designed using Primer Express v 2.0 software (Applied Biosystems). The C14ORF166 sense primer was 5'TGCATTGTCAGCAGTTTTTGA-3', and the antisense primer was 5'-TGACTGGCTTCTTGGTTTAGC-3'. For the $G A D P H$ gene, the sense primer was $5^{\prime}-$ TTGAGGTCAATGAAGGGGTC-3', and the antisense primer was 5'-GAAGGTGAAGGTCGGAGTCA-3'. Expression data were normalized to the geometric mean of the housekeeping gene GADPH to control the variability in expression levels and calculated as 2-[(Ct of C14ORF166)-(Ct of GADPH)], where $\mathrm{Ct}$ represents the threshold cycle for each transcript.

\section{Western blotting}

Sample preparation for immunoblotting was performed as previously described. Cells at 80 to $90 \%$ confluence were washed twice with ice-cold phosphate-buffered saline (PBS) and lysed on ice in radio immunoprecipitation assay buffer (RIPA; Cell Signaling Technology, Danvers, MA) containing
Table 1 Clinicopathological characteristics and tumor expression of C14ORF166 in patients with cervical cancer

\begin{tabular}{|c|c|}
\hline Characteristic & Number of cases $(\%)$ \\
\hline \multicolumn{2}{|l|}{ Age (years) } \\
\hline$<50$ & $114(77.0)$ \\
\hline$\geq 50$ & $34(23.0)$ \\
\hline \multicolumn{2}{|l|}{ FIGO stage } \\
\hline I & $51(34.5)$ \\
\hline II & $80(54.0)$ \\
\hline III & $15(10.1)$ \\
\hline IV & $2(1.4)$ \\
\hline \multicolumn{2}{|l|}{ Histological type } \\
\hline Squamous carcinoma & $143(96.6)$ \\
\hline Adenocarcinoma & $5(3.4)$ \\
\hline \multicolumn{2}{|c|}{ Pelvic lymph node metastasis } \\
\hline No & $115(77.7)$ \\
\hline Yes & $33(22.3)$ \\
\hline \multicolumn{2}{|c|}{ Expression of C14ORF166 } \\
\hline Low or none & $89(60.1)$ \\
\hline High & $59(39.9)$ \\
\hline \multicolumn{2}{|l|}{ Tumor size, $\mathrm{cm}$} \\
\hline$<4 \mathrm{~cm}$ & $71(48.0)$ \\
\hline$\geq 4 \mathrm{~cm}$ & $77(52.0)$ \\
\hline \multicolumn{2}{|l|}{ Tumor recurrence } \\
\hline No & $133(89.9)$ \\
\hline Yes & $15(10.1)$ \\
\hline \multicolumn{2}{|c|}{ Vital status (at last follow-up) } \\
\hline Alive & $127(85.8)$ \\
\hline Dead & $21(14.2)$ \\
\hline \multicolumn{2}{|l|}{ Differentiation grade } \\
\hline G1 & $3(2.0)$ \\
\hline G2 & $59(39.9)$ \\
\hline G3 & $86(58.1)$ \\
\hline \multicolumn{2}{|c|}{ Postoperative chemotherapy } \\
\hline No & $47(31.8)$ \\
\hline Yes & $101(68.2)$ \\
\hline \multicolumn{2}{|l|}{ Postoperative radiation } \\
\hline No & $92(62.2)$ \\
\hline Yes & $56(37.8)$ \\
\hline \multicolumn{2}{|c|}{ Squamous cell carcinoma antigen, $\mathrm{ng} / \mathrm{ml}$} \\
\hline$\leq 1.5$ & $93(62.8)$ \\
\hline$>1.5$ & $55(37.2)$ \\
\hline
\end{tabular}

complete protease inhibitor cocktail (Roche Applied Sciences, Mannheim, Germany). Fresh tissue samples were ground to powder in liquid nitrogen and lysed with SDS-PAGE sample buffer. Protein concentration was determined by the Bradford assay (Bio-Rad Laboratories, Hercules, CA). Equal amounts of proteins $(30 \mu \mathrm{g})$ were separated electrophoretically on $10.5 \%$ SDS/polyacrylamide gels and transferred onto PVDF 
membranes (Immobilon P, Millipore, Bedford, MA). Membranes were blocked with $5 \%$ fat-free milk in Tris-buffered saline containing $0.1 \%$ Tween-20 (TBS-T) for $1 \mathrm{~h}$ at room temperature. Membranes were probed with an antiC14ORF166 rabbit polyclonal antibody (1:2000, Proteintech) overnight at $4{ }^{\circ} \mathrm{C}$. After washing with TBS-T, the membrane was incubated with a secondary antibody against mouse immunoglobulin G. The membrane was washed, and protein was detected by enhanced chemiluminescence (Amersham Pharmacia Biotech) according to the manufacturer's instructions. An anti- $\alpha$-tubulin mouse monoclonal antibody $(1: 1000$; Santa Cruz Biotechnology, Santa Cruz, CA) was used to confirm equal loading.

\section{Immunohistochemical analysis}

Immunohistochemistry was done to examine C14ORF166 expression in 148 human cervical cancer specimens. Briefly, paraffin-embedded tissues were cut into 4-Am sections and baked at $60^{\circ} \mathrm{C}$ for $1 \mathrm{~h}$. The sections were deparaffinized with xylenes, rehydrated, then submerged into citrate antigenic retrieval buffer and microwaved for antigenic retrieval. The samples were then treated with $3 \%$ hydrogen peroxide in methanol to quench the endogenous peroxidase activity, followed by incubation with $1 \%$ bovine serum albumin to block the nonspecific binding. Finally, the sections were incubated with anti-C14ORF166 rabbit polyclonal antibody (1:200, Proteintech) overnight at $4{ }^{\circ} \mathrm{C}$. For negative controls, the primary antibody was replaced by normal goat serum. After washing, the tissue sections were then incubated with the biotinylated antimouse secondary antibody (Abcam), followed by further incubation with streptavidin-horseradishperoxidase complex (Abcam). The tissue sections were immersed in 3-amino-9-ethyl carbazole, counterstained with $10 \%$ Mayer's hematoxylin, dehydrated, and mounted in crystal mount.

The degree of immunostaining of formalin-fixed, paraffinembedded sections was reviewed and scored by three independent observers who were blinded to the histopathological features and patient data of the samples. The scores given by the three independent investigators were averaged and based on both the proportion of positively stained tumor cells and the intensity of staining. The intensity of protein expression was recorded as follows: 0 (no staining), 1 (weak staining, light yellow), 2 (moderate staining, yellowish brown), and 3 (strong staining, brown). The proportion of tumor cells was scored as follows: 1 ( $<10 \%$ positive tumor cells), $2(10-50 \%$ positive tumor cells), 3 (50-75\% positive tumor cells), and 4 ( $>75 \%$ positive tumor cells). The staining intensity and the proportion of positive cell scores for each section were multiplied (scored as $0,1,2,3,4,6,8,9$, or 12). Using this method of assessment, we evaluated the expression of C14ORF166 in cervical cancer tissue. Cut-off values for C14ORF166 were chosen on the basis of a measure of heterogeneity using the log-rank test with respect to overall survival (OS). An optimal cut-off value was identified as follows: a staining index score of $>6$ was utilized to define tumors with high C14ORF166 expression and $\leq 6$ suggested low C14ORF166 expression. To account for the inconsistencies in IHC stain intensities, the mean optical density (MOD) method, which was used for the scoring of the staining intensity, was applied in the current study.

\section{Statistical analysis}

All statistical analyses were conducted using the SPSS 16.0 statistical software packages. In the real-time PCR and Western blot analysis, the significance of mRNA and protein expression between cervical cancers and the adjacent normal tissues was analyzed by $t$ test. We analyzed the relationship between expression of C14ORF166 protein, clinicopathologic features, and the clinical prognosis. The chi-square test and Fisher's exact test were used to analyze the relationship between C14ORF166 expression and clinicopathological characteristics. Bivariate correlations between study variables were calculated by association analysis. Survival curves were plotted by the Kaplan-Meier method and compared using the log-rank test. Using the Cox proportional hazards regression model in the univariate and multivariate analysis, the significance of various variables which were mentioned above for survival was analyzed to predict prognosis in clinical practice. In all cases, a $P$ value of less than 0.05 was considered to be statistically significant.

\section{Results}

\section{C14ORF166 is overexpressed in cervical cancer cell lines}

RT-PCR and Western blotting were performed to determine C14ORF166 mRNA and protein expression in eight cervical cancer cell lines (HeLa, SiHa, C33A, MS751, CasKi, HeLa229, HCC94, and ME-180) and normal cervical cell lines (NC). As shown in Fig. 1a and b, both C14ORF166 mRNA and protein were expressed at high levels in all cervical cancer cell lines tested compared to normal cervical lines.

\section{C14ORF166 is overexpressed in human cervical cancer}

To evaluate the expression of C14ORF166 in human cervical cancer, RT-PCR and Western blotting were performed on cervical cancer specimens of eight patients and their paired adjacent noncancerous tissues. All eight human cervical cancer tissue samples expressed high levels of C14ORF166 mRNA and protein; whereas, C14ORF166 was expressed at low levels in the adjacent normal tissues (Fig. 2a, b). 


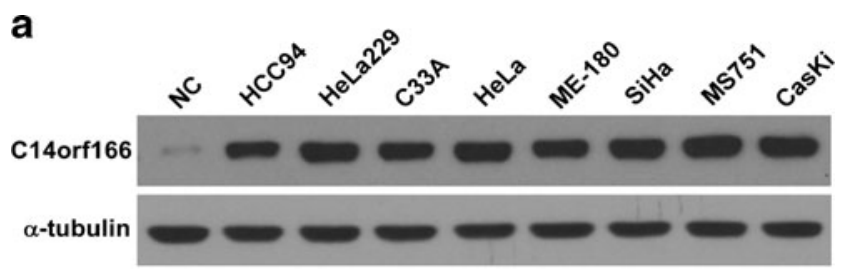

b

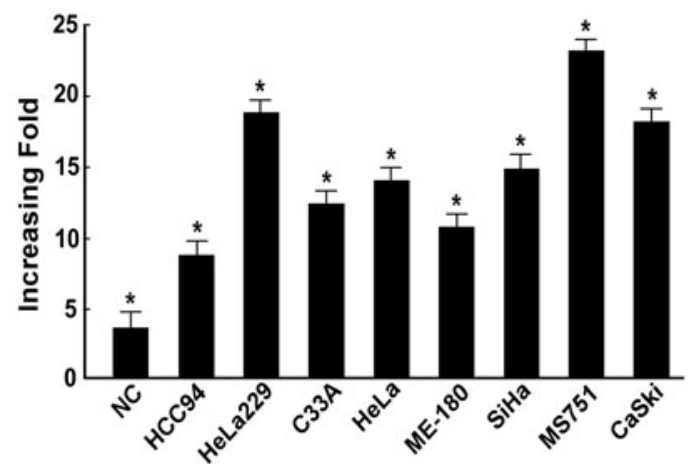

Fig. 1 Overexpression of C14ORF166 mRNA and protein in cervical cancer cell lines. a, b Expression of C14ORF166 mRNA and protein in cervical cancer cell lines (HCC94, HeLa229, C33A, HeLa, ME-180, $\mathrm{SiHa}, \mathrm{MS751}$, CasKi) and normal cervical cell lines were examined by Western blotting (a) and qPCR (b). Expression levels were normalized against GAPDH respectively. Error bars represent the standard deviation of the mean (SD) calculated from three parallel experiments. ${ }^{*} p<0.05$

C14ORF166 protein expression was assessed in 148 paraffin-embedded archived cervical cancer tissues by immunohistochemical staining using an antibody against human C14ORF166. Either no immunoreactivity or only weak staining was observed in the adjacent noncancerous tissues and normal cervical tissues; whereas, C14ORF166 was expressed at high levels in the cervical cancer tissues (Fig. 2c). In the tumor tissues, C14ORF166 was primarily localized in the tumor cell nuclei with strong cytoplasmic staining occasionally observed (Fig. 3a). High levels of C14ORF166 protein expression were observed in 59/148 patients (39.9\%), and weak or no staining was observed in 89 patients $(60.1 \%$; Table 1$)$. Furthermore, the statistical analyses of the average mean optical density (MOD) of C14ORF166 staining in normal cervical tissues and cervical cancer specimens at different clinical stages revealed that C14ORF166 expression increased with advancing FIGO stage in cervical cancer (Fig. 3).

\section{C14ORF166 expression correlates with the clinicopathologic features of cervical cancer}

The correlation between expression of C14ORF166 protein and the clinicopathological features of cervical cancer were analyzed using the chi-square test and Fisher's exact test (Table 2). High expression of C14ORF166 protein was significantly associated with FIGO stage $(P<0.001)$, vital status $(P=0.026)$, tumor size $(P=0.034)$, pelvic lymph node metastasis $(P<0.001)$, and serum squamous cell carcinoma antigen level $(P=0.035)$. Patients with highly expressed C14ORF166 showed a tendency to receive postoperative chemotherapy $(P=0.005)$ and postoperative radiation $(P=0.008)$. However, there were no statistically significant correlations between C14ORF166 protein expression and other clinicopathologic features such as patient age, histological differentiation, and recurrence.

Association analysis was performed to confirm the correlations between C14ORF166 expression and the clinicopathological features of cervical cancer. As shown in Table 3, statistically significant correlations were observed between C14ORF166 expression and FIGO stage $(0.561 ; P<0.001)$, pelvic lymph node metastasis $(0.465 ; P<0.001)$, tumor size (0.172; $P=0.034)$, and the serum squamous cell carcinoma antigen level $(0.171 ; P=0.035)$. In addition, patients with highly expressed C14ORF166 showed a tendency to receive postoperative chemotherapy $(0.224 ; P=0.005)$ and postoperative radiation $(0.213 ; P=0.008)$.

\section{Increased C14ORF166 expression is associated with poor prognosis in cervical cancer}

Kaplan-Meier survival analysis and the log-rank test indicated that a high level of C14ORF166 protein expression was associated with significantly poorer 5 -year overall survival (OS, $P<0.001$; Fig. 4a) and 5-year disease-free survival (DFS, $P<0.001$; Fig. $4 \mathrm{~b}$ ) in patients with cervical cancer. We observed that the cumulative 5 -year overall survival rate was $87 \%$ (95\% CI, 86.9 87.1\%) in the low C14ORF166 group; whereas, it was only $65 \%(95 \% \mathrm{CI}, 67.6 \sim 68.0 \%)$ in the high C14ORF166 group.

In subgroup analysis, high-level expression of C14ORF166 was associated with significantly poorer OS in patients without pelvic lymph node metastasis $(P=0.041$; Fig. $4 \mathrm{c})$ and patients with stages I and II disease $(P=0.027$; Fig. 4 d) but not in patients with stages III and IV disease $(P=$ 0.414; data not shown); the lack of a statistically significant association may be due to the limited number of patients in each subset.

Moreover, univariate Cox regression and multivariate survival analysis indicated that C14ORF166 expression $(P=$ $0.036)$, FIGO stage $(P=0.009)$, recurrence $(P=0.003)$, and pelvic lymph node metastasis $(P=0.013)$ were independent prognostic factors for poor overall survival (Table 4). Therefore, these findings indicate that C14ORF166 may represent a valuable prognostic marker in cervical cancer.

\section{Discussion}

In this study, we provide the first evidence that increased expression of C14ORF166 is a common feature and may represent a potential prognostic marker in cervical cancer. 
Fig. 2 Overexpression of C14ORF166 mRNA and protein in cervical cancer tissues. a Representative images of Western blotting analyses of C14ORF166 protein expression in eight matched pairs of cervical cancer (T) and adjacent noncancerous tissues. The expression level was normalized by $\alpha$-tubulin expression. b Average T/N ratios of C14ORF166 mRNA expression in paired cervical cancer ( $\mathrm{T}$ ) and adjacent noncancerous tissues $(\mathrm{N})$ were quantified by qPCR and normalized against GAPDH. Error bars represent the standard deviation of the mean (SD) calculated from three parallel experiments. $\mathbf{c}$ Immunohistochemical assay of C14ORF166 protein expression in eight pairs of matched cervical cancer tissues. ${ }^{*} p<0.05$ a

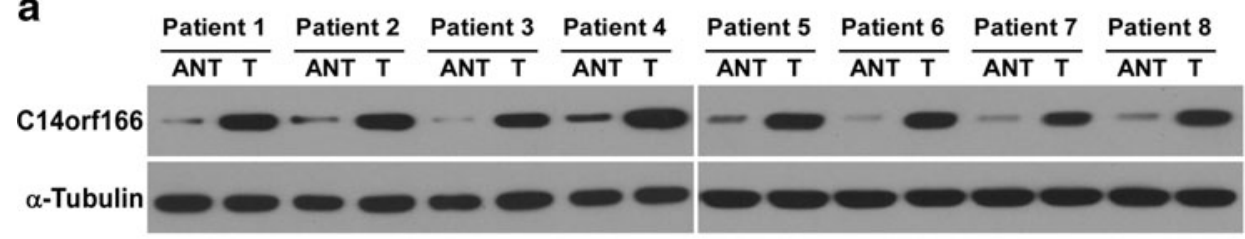

b

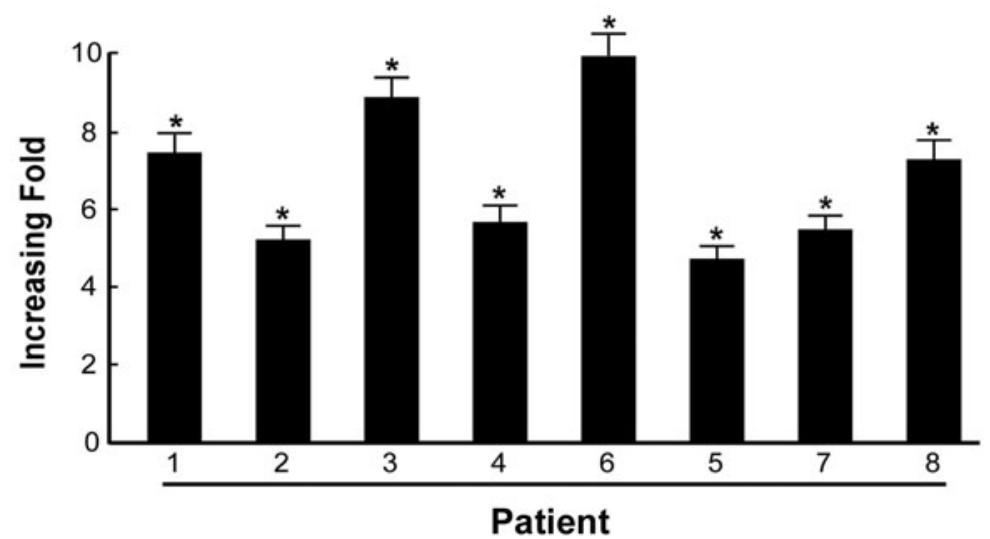

C Patient 1 ANT $\quad$ T

Patient 5

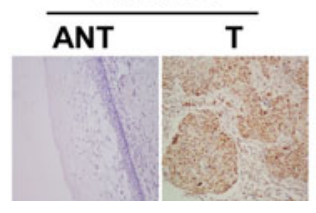

Patient 2

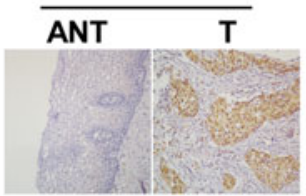

Patient 3

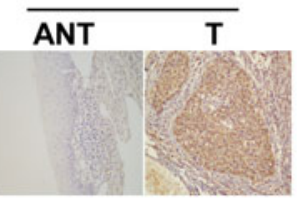

Patient 7

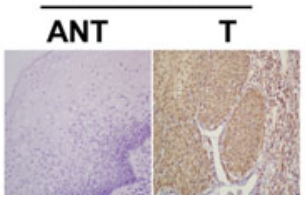

Patient 4

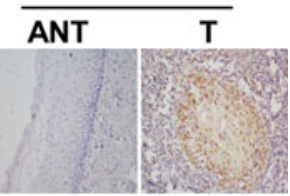

Patient 8 $\begin{array}{ll}\text { ANT } & T\end{array}$
Interestingly, C14ORF166 protein expression was also significantly associated with pelvic lymph node metastasis, clinical stage, vital status, tumor size, and serum squamous cell carcinoma antigen level.

In the present study, overexpression of C14ORF166 was not only observed in HPV-positive cervical cancer cell lines, such as HeLa, SiHa, and CasKi, but also in the HPV-negative cervical cancer cell line C33A. Moreover, immunohistochemical analysis revealed that C14ORF166 was overexpressed in the majority of human cervical cancer tissue specimens tested, in agreement with previous studies in brain cancer [10] and pancreatic cancer $[11,12]$. However, the molecular mechanisms responsible for overexpression of C14ORF166 in cancer remain largely unknown.

A number of potential biomarkers, including tissue polypeptide antigen (TPA) and tissue polypeptidespecific antigen (TPS) have been suggested to have prognostic value in cervical cancer; however, the data concerning these antigens is conflicting and further studies are required [16-18]. In this cohort, we showed that aberrant expression of C14ORF166 protein was associated with significantly poorer 5-year OS and DFS. Multivariate Cox regression analysis revealed that a high level of C14ORF166 was an independent prognostic marker for cervical cancer. Taken together, our study indicated that C14ORF166 could be a novel prognostic biomarker to identify cervical cancer patients with poor clinical outcome.

In this study, high expression of C14ORF166 protein correlated significantly with advanced tumor stage, larger tumor size, death, lymph node metastasis, and poorer survival, suggesting that C14ORF166 may not only play a role in promoting the growth of the primary tumor but may also be associated with the development of lymph node metastasis in cervical cancer. Associations between C14ORF166 protein expression and the clinical features of other types of cancer have been reported. Guo et al. [11] and Cur et al. [12] showed that expression of C14ORF166 was significantly associated with an aggressive phenotype in pancreatic carcinoma, and Wang et al. [10] reported that expression of C14ORF166 was 
Fig. 3 a The expression of C14ORF166 protein in cervical cancer tissues from patients at different clinical stages. $\mathbf{b}$ The average MOD of C14ORF166 staining between the normal cervical tissues (four cases) and different clinical stage cervical tissues (randomly picked 10 cases per stage) were statistically quantified. The average MOD of C14ORF166 staining increases as cervical cancer progresses to more advanced stages $(P<0.001)$. Error bars represent mean \pm SD from three independent experiments.
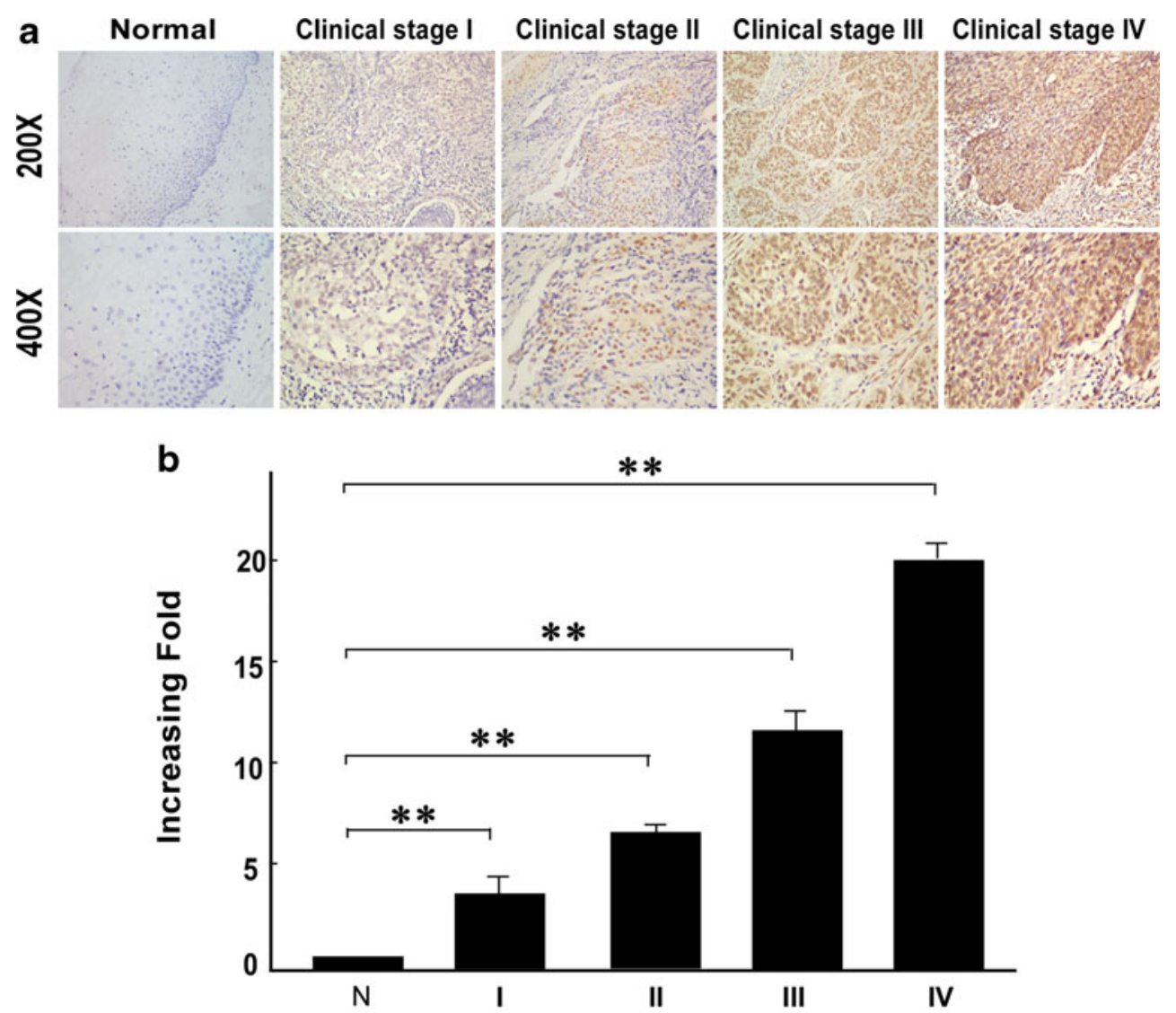

\section{Clinical Stage}

associated with poor prognostic factors in brain cancer. This evidence indicates that C14ORF166 may play a role in the pathogenesis of various types of cancer.

Recently, Chen et al. [13] investigated the JAK2/STAT3 pathway in esophageal cancer using immunoprecipitation assays and demonstrated C14ORF166 was a binding partner of JAK2. JAK2, a member of the Janus (JAK) family of nonreceptor protein tyrosine kinases, functions as a prototypical kinase to mediate the phosphorylation of signal transducer and activator of transcription 3 (STAT3), thus regulating the JAK2/STAT3 signaling pathway [19, 20]. Activation of the JAK2/STAT3 pathway is associated with inflammation, and inflammation subsequent to viral infection is one factor that initiates and promotes the development of cancer [21-25]. Hyperactivation of inflammatory pathways plays an important role in cervical cancer tumorgenesis, and promotes progression from low-grade lesions to invasive cervical cancer [26]. Additionally, Sobti et al. [27] indicated a potentially interactive effect between HPV16/18 and activation of the JAK2/ STAT3 pathway in cervical carcinogenesis. Furthermore, it was reported that the JAK2/STAT3 pathway regulates cervical cancer progression $[14,15]$. These studies indicate that overexpression of C14ORF166 may affect the development and progression of cervical cancer by modulating the JAK2/ STAT3 signaling pathways; further characterization of these processes may provide new insight and novel targets for the treatment of cervical cancer. The molecular mechanism that links C14ORF166 to tumor progression in cervical cancer remains to be elucidated, and further studies are warranted.

It is widely recognized that various treatment strategies lead to different clinical outcomes in patients with cervical cancer. Currently, assessment of lymph node metastasis provides important information for determining the appropriate treatment approach, such as surgical resection and chemoradiation [28, 29]. Moreover, lymph node metastasis is an important cause of cervical cancer-related mortality [30]. Noordhuis et al. [31] found that patients with early-stage cervical cancer who did not have lymph node metastasis had a 5year overall survival rate of $90 \%$ compared to only $65 \%$ for patients with lymph node metastasis. However, there are no accurate and efficient techniques for diagnosing pelvic lymph node metastasis to help gynecologic oncologists select the appropriate treatment and avoid unnecessary surgical intervention [32]. Interestingly, we observed that C14ORF166 
Table 2 Correlation between C14ORF166 expression and the clinicopathologic features of cervical cancer

\begin{tabular}{|c|c|c|c|c|c|c|}
\hline \multirow[t]{2}{*}{ Characteristic } & & \multirow[t]{2}{*}{ Total } & \multicolumn{2}{|l|}{ C14ORF166 } & \multirow{2}{*}{$\begin{array}{l}\text { Chi-squared } \\
\text { test } P \text { value }\end{array}$} & \multirow{2}{*}{$\begin{array}{l}\text { Fisher's exact } \\
\text { test } P \text { value }\end{array}$} \\
\hline & & & $\begin{array}{l}\text { No or weak } \\
\text { expression }\end{array}$ & $\begin{array}{l}\text { Moderate or } \\
\text { strong expression }\end{array}$ & & \\
\hline Age (years) & $\begin{array}{l}<50 \\
\geq 50\end{array}$ & $\begin{array}{l}114 \\
34\end{array}$ & $\begin{array}{l}67(45.3) \\
22(14.9)\end{array}$ & $\begin{array}{l}47(31.8) \\
12(8.1)\end{array}$ & 0.535 & 0.557 \\
\hline \multirow[t]{3}{*}{ FIGO stage } & $\begin{array}{l}\text { I } \\
\text { II }\end{array}$ & $\begin{array}{l}51 \\
80\end{array}$ & $\begin{array}{l}46(31.1) \\
42(28.4)\end{array}$ & $\begin{array}{l}5(3.4) \\
38(25.7)\end{array}$ & $<0.001$ & - \\
\hline & III & 15 & $1(0.7)$ & $14(9.4)$ & & \\
\hline & IV & 2 & $0(0)$ & $2(1.4)$ & & \\
\hline Pelvic lymph node metastasis & $\begin{array}{l}\text { Absent } \\
\text { Present }\end{array}$ & $\begin{array}{l}115 \\
33\end{array}$ & $\begin{array}{l}85(57.4) \\
4(2.7)\end{array}$ & $\begin{array}{l}30(20.3) \\
29(19.6)\end{array}$ & $<0.001$ & $<0.001$ \\
\hline Tumor size & $\begin{array}{l}<4 \mathrm{~cm} \\
\geq 4 \mathrm{~cm}\end{array}$ & $\begin{array}{l}71 \\
77\end{array}$ & $\begin{array}{l}49(33.1) \\
40(27.0)\end{array}$ & $\begin{array}{l}22(14.9) \\
37(25.0)\end{array}$ & 0.034 & 0.044 \\
\hline Tumor recurrence & $\begin{array}{l}\text { No } \\
\text { Yes }\end{array}$ & $\begin{array}{l}133 \\
15\end{array}$ & $\begin{array}{l}81(54.0) \\
8(5.4)\end{array}$ & $\begin{array}{l}52(36.5) \\
7(4.1)\end{array}$ & 0.570 & 0.588 \\
\hline Vital status (at last follow-up) & $\begin{array}{l}\text { Alive } \\
\text { Dead }\end{array}$ & $\begin{array}{l}127 \\
21\end{array}$ & $\begin{array}{l}81(54.7) \\
8(5.4)\end{array}$ & $\begin{array}{l}46(31.1) \\
13(8.8)\end{array}$ & 0.026 & 0.032 \\
\hline \multirow[t]{2}{*}{ Differentiation } & $\begin{array}{l}\text { G1 } \\
\text { G2 }\end{array}$ & $\begin{array}{l}3 \\
59\end{array}$ & $\begin{array}{l}2(1.4) \\
36(24.3)\end{array}$ & $\begin{array}{l}1(0.7) \\
23(15.5)\end{array}$ & 0.952 & - \\
\hline & G3 & 86 & $51(34.5)$ & $35(23.6)$ & & \\
\hline Postoperative chemotherapy & $\begin{array}{l}\text { No } \\
\text { Yes }\end{array}$ & $\begin{array}{l}47 \\
101\end{array}$ & $\begin{array}{l}36(24.3) \\
53(35.8)\end{array}$ & $\begin{array}{l}11(7.4) \\
48(32.4)\end{array}$ & 0.005 & 0.007 \\
\hline Postoperative radiation & $\begin{array}{l}\text { No } \\
\text { Yes }\end{array}$ & $\begin{array}{l}92 \\
56\end{array}$ & $\begin{array}{l}63(42.6) \\
26(17.5)\end{array}$ & $\begin{array}{l}29(19.6) \\
30(20.3)\end{array}$ & 0.008 & 0.010 \\
\hline Squamous cell carcinoma antigen, $\mathrm{ng} / \mathrm{ml}$ & $\begin{array}{l}\leq 1.5 \\
>1.5\end{array}$ & $\begin{array}{l}93 \\
55\end{array}$ & $\begin{array}{l}62(41.9) \\
27(18.2)\end{array}$ & $\begin{array}{l}31(21.0) \\
28(18.9)\end{array}$ & 0.035 & 0.039 \\
\hline
\end{tabular}

was significantly associated with pelvic lymph node metastasis $(P<0.001)$. In accordance with these results, Guo et al. [11] and Cui et al. [12] previously reported that C14ORF166 was a novel lymph node metastasis-associated protein in pancreatic cancer. Hence, we suggest that C14ORF166 has potential as a novel predictor of pelvic lymph node metastasis; additional multi-center prospective studies are required to validate this hypothesis. Additionally, further study of the role of C14ORF166 in invasion and metastasis may help to clarify the mechanisms that regulate metastasis and identify novel therapeutic targets for cervical cancer.

Squamous cell carcinoma antigen (SCC-Ag) is commonly employed in the clinic for cervical cancer screening and as an important prognostic factor for patient survival [33]. High serum SCC-Ag levels have been associated with pelvic lymph node metastasis, tumor stage, tumor size, recurrence, and
Table 3 Correlation between C14ORF166 expression and the clinicopathological characteristics of patients with cervical cancer

\begin{tabular}{lll}
\hline Variable & \multicolumn{2}{l}{ C14ORF166 expression } \\
\cline { 2 - 3 } & Association coefficient & $P$ value \\
\hline Age & 0.051 & 0.535 \\
FIGO Stage & 0.561 & $<0.001$ \\
Pelvic lymph node metastasis & 0.465 & $<0.001$ \\
Tumor size & 0.172 & 0.034 \\
Recurrence & 0.047 & 0.570 \\
Vital status & 0.180 & 0.026 \\
Differentiation grade & 0.026 & 0.952 \\
Postoperative chemotherapy & 0.224 & 0.005 \\
Postoperative radiation & 0.213 & 0.008 \\
Squamous cell carcinoma antigen, $\mathrm{ng} / \mathrm{ml}$ & 0.171 & 0.035 \\
\hline
\end{tabular}


Fig. 4 Survival curves of patients with cervical carcinoma, subdivided according to C14ORF166 protein expression (log-rank test). a, b OS (a) and 5year DFS (b) rates for cases with high C14ORF166 expression versus those for cases with low C14ORF166 expression levels in all patients. c, $\mathbf{d}$ OS rate for without lymph node metastasis cases (c) and clinical stage I/II cases (d) with high C14ORF166 expression versus those for cases with low C14ORF166 expression levels.
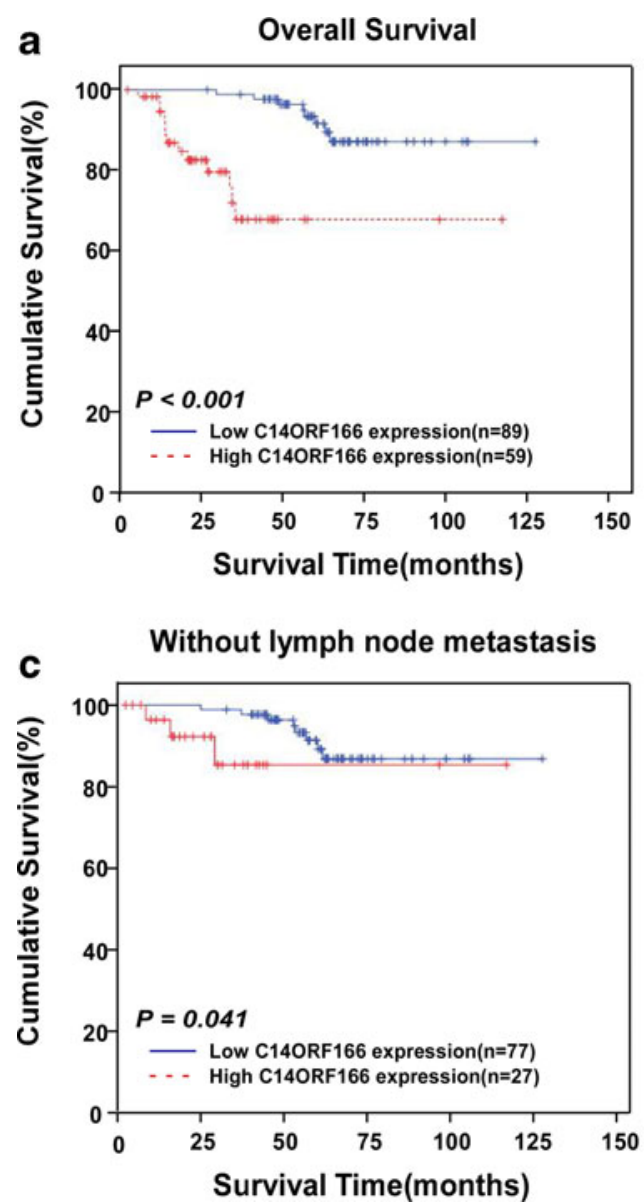
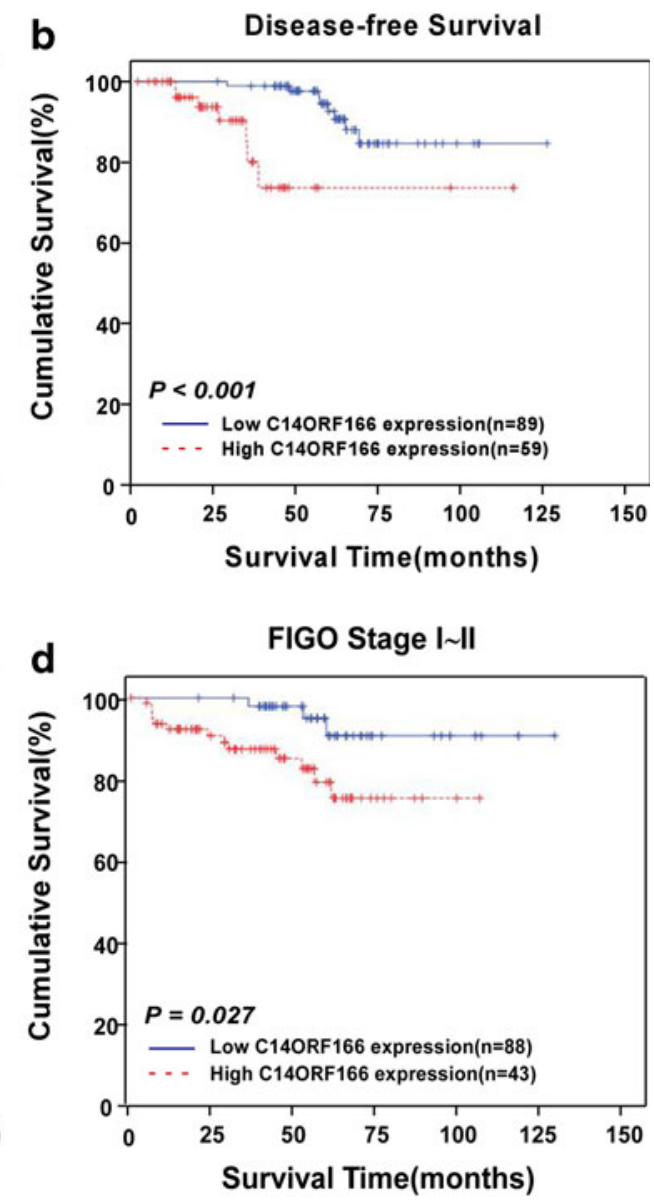

survival in cervical cancer [34-36]. However, SCC-Ag is neither cervix-specific nor malignancy-specific; the serum levels of SCC-Ag are significantly elevated in patients with lung cancer, esophageal squamous cell carcinoma, and head and neck squamous cell carcinoma [37-39]. Torre et al. [40] also indicated that serum SCC-Ag was elevated in patients with

Table 4 Univariate and multivariate analyses of prognostic factors in cervical cancer using a Cox regression model

\begin{tabular}{|c|c|c|c|c|c|c|}
\hline & \multicolumn{3}{|c|}{ Univariate analysis } & \multicolumn{3}{|c|}{ Multivariate analysis } \\
\hline & No. of patients & $P$ & Regression coefficient (SE) & $P$ & Relative risk & $95 \%$ confidence interval \\
\hline \multicolumn{7}{|c|}{ Pelvic lymph node metastasis } \\
\hline Absent & 115 & $<0.001$ & $1.937(0.453)$ & 0.013 & 3.693 & $1.311-10.403$ \\
\hline Present & 33 & & & & & \\
\hline \multicolumn{7}{|l|}{ FIGO stage } \\
\hline I & 51 & & & & & \\
\hline II & 80 & $<0.001$ & $1.155(0.309)$ & 0.009 & 2.475 & $1.251-4.898$ \\
\hline III & 15 & & & & & \\
\hline IV & 2 & & & & & \\
\hline \multicolumn{7}{|l|}{ C14ORF166 } \\
\hline Low expression & 89 & $<0.001$ & $2.104(0.503)$ & 0.036 & 4.017 & $1.095-14.731$ \\
\hline High expression & 59 & & & & & \\
\hline Recurrence & & 0.004 & $1.396(0.485)$ & 0.003 & 4.419 & $1.659-11.768$ \\
\hline No & 133 & & & & & \\
\hline Yes & 15 & & & & & \\
\hline
\end{tabular}


benign conditions including tuberculosis, eczema, and pemphigus. Kim et al. [41] demonstrated that increased serum SCC-Ag $(>2.0 \mathrm{ng} / \mathrm{mL})$ may be predictive for lymph node metastases in early-stage cervical carcinoma, and Takeda et al. [42] reported that serum SCC-Ag levels over $1.5 \mathrm{ng} / \mathrm{ml}$ were significantly associated with lymph node metastasis. However, the cutoff levels for SCC-Ag varied from study to study resulting in vastly different sensitivity and specificity values for this marker [34, 43, 44], and a normal pretreatment SCC-Ag level does exclude the presence of lymph node metastases in cervical cancer [45]. Therefore, the predictive value of serum SCC-Ag for pelvic lymph node metastases in cervical carcinoma is unsatisfactory [17]. Herein, we found that C14ORF166 was strongly associated with and may therefore represent a valuable biomarker of pelvic lymph node metastasis. Thus, C14ORF166 may be useful for evaluating prognosis and guiding follow-up therapy in cervical cancer. Additionally, C14ORF166 can be detected in the serum of patients with pancreatic cancer [9]; however, we did not explore the expression of C14ORF166 in the serum of patients with cervical cancer. Therefore, further investigation is required to confirm whether C14ORF166 has potential as predictive biomarker for identifying patients with pelvic lymph node metastasis.

\section{Conclusion}

In our study, we report that the expression of C14ORF166 is upregulated in cervical cancer cells and human surgical specimens. Additionally, C14ORF166 was significantly associated with pelvic lymph node metastasis, clinical stage, tumor size, vital status, and the serum squamous cell carcinoma antigen level. Patients with highly expressed C14ORF166 showed a tendency to receive postoperative chemotherapy and postoperative radiation. Multivariate analysis revealed that C14ORF166 was an independent prognostic factor for cervical cancer. Taken together, these results suggest that C14ORF166 may play an important role in the development and progression of human cervical carcinoma. C14ORF166 may represent a potential biomarker for lymph node metastasis in cervical cancer, which may help to identify patients at high risk and establish a rationale for selecting appropriate therapeutic strategies.

Open Access This article is distributed under the terms of the Creative Commons Attribution 4.0 International License (http://creativecommons.org/licenses/by/4.0/), which permits unrestricted use, distribution, and reproduction in any medium, provided you give appropriate credit to the original author(s) and the source, provide a link to the Creative Commons license, and indicate if changes were made.

\section{References}

1. Siegel R, Naishadham D, Jemal A. Cancer statistics. 2012. CA Cancer J Clin. 2012;62:10-29.

2. de Guadalupe C-LM, Hernández-Gallegos E, Vázquez-Sánchez AY, Gariglio P, Camacho J. Antiproliferative and proapoptotic effects of astemizole on cervical cancer cells. Int J Gynecol Cancer. 2014;24:824-8.

3. Shin HJ, Joo J, Yoon JH, Yoo CW, Kim JY. Physical status of human papillomavirus integration in cervical cancer is associated with treatment outcome of the patients treated with radiotherapy. PLoS One. 2014;9, e78995.

4. Jiménez-Wences H, Peralta-Zaragoza O, Fernández-Tilapa G. Human papilloma virus, DNA methylation and microRNA expression in cervical cancer. Oncol Rep. 2014;31:2467-76.

5. Gadducci A, Guerrieri ME, Greco C. Tissue biomarkers as prognostic variables of cervical cancer. Crit Rev Oncol Hematol. 2013;86:104-29.

6. Wang J, Gu Y, Wang L, Hang X, Gao Y, Wang H, et al. HUPO BPP pilot study: a proteomics analysis of the mouse brain of different developmental stages. Proteomics. 2007;7:4008-15.

7. NCCN. NCCN clinical practice guidelines in oncology-cervical cancer. 2011; V1 http://www.nccn.org/professionals/physician gls/f guidelines.asp (17 May 2011, date last accessed).

8. Huarte M, Sanz-Ezquerro JJ, Roncal F, Ortín J, Nieto A. PA subunit from influenza virus polymerase complex interacts with a cellular protein with homology to a family of transcriptional activators. J Virol. 2001;75:8597-604.

9. Pérez-González A, Pazo A, Navajas R, Ciordia S, RodriguezFrandsen A, Nieto A. hCLE/C14orf166 associates with DDX1HSPC117-FAM98B in a novel transcription-dependent shuttling RNA-transporting complex. PLoS One. 2014;9, e90957.

10. Wang J, Gu Y, Wang L, et al. HUPO BPP pilot study: a proteomics analysis of the mouse brain of different developmental stages. Proteomics. 2007;7:4008-15.

11. Guo J, Wang W, Liao P, et al. Identification of serum biomarkers for pancreatic adenocarcinoma by proteomic analysis. Cancer Sci. 2009; 100:2292-301.

12. Cui Y, Wu J, Zong M, et al. Proteomic profiling in pancreatic cancer with and without lymph node metastasis. Int J Cancer. 2009;124: 1614-21.

13. Chen X, Ying Z, Lin X, et al. Acylglycerol kinase augments JAK2/ STAT3 signaling in esophageal squamous cells. J Clin Invest. 2013;123:2576-89.

14. $\mathrm{Hu}$ Y, Chen H, Duan C, et al. Deficiency of Erbin induces resistance of cervical cancer cells to anoikis in a STAT3-dependent manner. Oncogenesis. 2013;2, e52.

15. Siejka A, Schally AV, Barabutis N. Activation of Janus kinase/ signal transducer and activator of transcription 3 pathway by growth hormone-releasing hormone. Cell Mol Life Sci. 2010;67: 959-64.

16. Sturgeon CM, Duffy MJ, Hofmann BR, et al. National Academy of Clinical Biochemistry Laboratory Medicine Practice Guidelines for use of tumor markers in liver, bladder, cervical, and gastric cancers. Clin Chem. 2010;56:e1-48.

17. Juang CM, Wang PH, Yen MS, Lai CR, Ng HT, Yuan CC. Application of tumor markers CEA, TPA, and SCC-Ag in patients with low-risk FIGO stage IB and IIA squamous cell carcinoma of the uterine cervix. Gynecol Oncol. 2000;76:103-6.

18. Gaarenstroom KN, Kenter GG, Bonfrer JM, et al. Can initial serum cyfra 21-1, SCC antigen, and TPA levels in squamous cell cervical cancer predict lymph node metastases or prognosis? Gynecol Oncol. 2000;77:164-70.

19. Yu H, Pardoll D, Jove R. STATs in cancer inflammation and immunity: a leading role for STAT3. Nat Rev Cancer. 2009;9:798-809. 
20. Yu H, Jove R. The STATs of cancer-new molecular targets come of age. Nat Rev Cancer. 2004;4:97-105.

21. Zhang ZH, Yu LJ, Hui XC, et al. Hydroxy-safflor yellow A attenuates $A \beta 1-42$-induced inflammation by modulating the JAK2/STAT3/NF-kB pathway. Brain Res. 2014;1563:72-80.

22. Saravanan S, Hairul Islam VI, Prakash Babu N, et al. Swertiamarin attenuates inflammation mediators via modulating NF- $\mathrm{kB} / \mathrm{I} \mathrm{\kappa B}$ and JAK2/STAT3 transcription factors in adjuvant induced arthritis. Eur J Pharm Sci. 2014;56:70-86.

23. Zeng KW, Wang S, Dong X, Jiang Y, Jin HW, Tu PF. Sesquiterpene dimmer (DSF-27) inhibits the release of neuroinflammatory mediators from microglia by targeting spleen tyrosine kinase (Syk) and Janus kinase 2 (Jak2): Two major non-receptor tyrosine signaling proteins involved in inflammatory events. Toxicol Appl Pharmacol. 2014;275:244-56.

24. Zeng KW, Wang S, Dong X, Jiang Y, Tu PF. Sesquiterpene dimer (DSF-52) from Artemisia argyi inhibits microglia-mediated neuroinflammation via suppression of NF- $\mathrm{KB}, \mathrm{JNK} / \mathrm{p} 38 \mathrm{MAPKs}$ and Jak2/Stat3 signaling pathways. Phytomedicine. 2014;21:298-306.

25. Deivendran S, Marzook KH, Radhakrishna PM. The role of inflammation in cervical cancer. Adv Exp Med Biol. 2014;816: 377-99.

26. Parida S, Mandal M. Inflammation induced by human papillomavirus in cervical cancer and its implication in prevention. Eur $\mathrm{J}$ Cancer Prev. April 2014.

27. Sobti RC, Singh N, Hussain S, Suri V, Bharti AC, Das BC, Overexpression of STAT3 in HPV-mediated cervical cancer in a north Indian population. Mol Cell Biochem. 2009;330:193-9.

28. Geirsson RT. Progesterone and an aftermath to FIGO2009. Acta Obstet Gynecol Scand. 2009;88:1178-9.

29. Zhang L, Huang H, Zhang L, et al. URG4 overexpression is correlated with cervical cancer progression and poor prognosis in patients with early-stage cervical cancer. BMC Cancer. 2014;14:885.

30. Wang W, Jia HL, Huang JM, et al. Identification of biomarkers for lymph node metastasis in early-stage cervical cancer by tissuebased proteomics. Br J Cancer. 2014;110:1748-58.

31. Noordhuis MG, Fehrmann RS, Wisman GB, et al. Involvement of the TGF-beta and betacatenin pathways in pelvic lymph node metastasis in early-stage cervical cancer. Clin Cancer Res. 2011;17: 1317-30.

32. Li Z, Yu CP, Zhong Y, et al. Sam68 expression and cytoplasmic localization is correlated with lymph node metastasis as well as prognosis in patients with early-stage cervical cancer. Ann Oncol. 2012;23:638-46.
33. Jeong BK, Huh SJ, Choi DH, Park W, Bae DS, Kim BG. Prognostic value of different patterns of squamous cell carcinoma antigen level for the recurrent cervical cancer. Cancer Res Treat. 2013;45:48-54.

34. Jeong BK, Choi DH, Huh SJ, Park W, Bae DS, Kim BG. The role of squamous cell carcinoma antigen as a prognostic and predictive factor in carcinoma of uterine cervix. Radiat Oncol J. 2011;29:191-8.

35. Pang X, Zhang Y, Wei H, et al. Expression and effects of highmobility group box 1 in cervical cancer. Int J Mol Sci. 2014;15: 8699-712.

36. Lee YY, Choi CH, Sung CO, et al. Prognostic value of pretreatment circulating monocyte count in patients with cervical cancer: comparison with SCC-Ag level. Gynecol Oncol. 2012;124:927.

37. Li J, Chen P, Mao CM, Tang XP, Zhu LR. Evaluation of diagnostic value of four tumor markers in bronchoalveolar lavage fluid of peripheral lung cancer. Asia Pac J Clin Oncol. 2014;10:141-8.

38. Cao X, Zhang L, Feng GR, et al. Preoperative Cyfra21-1 and SCC$\mathrm{Ag}$ serum titers predict survival in patients with stage II esophageal squamous cell carcinoma. J Transl Med. 2012;10:197-203.

39. Deng Z, Hasegawa M, Yamashita Y, et al. Prognostic value of human papillomavirus and squamous cell carcinoma antigen in head and neck squamous cell carcinoma. Cancer Sci. 2012;103: 2127-34.

40. Torre GC. SCC antigen in malignant and nonmalignant squamous lesions. Tumour Biol. 1998;19:517-26.

41. Kim YT, Yoon BS, Kim JW, Kim SH, Kwon JY, Kim JH. Pretreatment levels of serum squamous cell carcinoma antigen and urine polyamines in women with squamous cell carcinoma of the cervix. Int J Gynaecol Obstet. 2005;91:47-52.

42. Takeda M, Sakuragi N, Okamoto K, et al. Preoperative serum SCC, CA125, and CA19-9 levels and lymph node status in squamous cell carcinoma of the uterine cervix. Acta Obstet Gynecol Scand. 2002;81:451-7.

43. Gaarenstroom KN, Bonfrer JM, Korse CM, Kenter GG, Kenemans P. Value of Cyfra 21-1, TPA, and SCC-Ag in predicting extracervical disease and prognosis in cervical cancer. Anticancer Res. 1997;17:2955-8.

44. Chen J, Yao D, Li Y, et al. Serum microRNA expression levels can predict lymph node metastasis in patients with early-stage cervical squamous cell carcinoma. Int J Mol Med. 2013;32:557-67.

45. Sturgeon CM, Duffy MJ, Hofmann BR, et al. National Academy of Clinical Biochemistry Laboratory Medicine Practice Guidelines for use of tumor markers in liver, bladder, cervical, and gastric cancers. Clin Chem. 2010;56:e1-48. 